\title{
Research Progress on Catalytic Pyrolysis Technology for Liquid Fuels
}

\author{
SONG Ge $e^{1, a}$ ZHOU Weihong ${ }^{1, b^{*}}$ \\ ${ }^{1}$ School of Civil Engineering, University of Science and Technology Liaoning, \\ Anshan 114044, China \\ a2036053633@qq.com \\ bzwh_0190@sina.com
}

Key words: biofuels; pyrolysis mechanism; pyrolysis reactor; bio-oil; catalytic pyrolysis Abstract: The development of bio-fuels were introduced, and it has greatly potential application. Pyrolysis process was benefit for the second-generation biofuels. The reaction mechanism of pyrolysis were summarized elaborately in this review. Main pyrolysis reactors and their research status were described, at the same time, analyzed the characteristics of bio-oil and upgraded by catalytic pyrolysis. The future of biomass catalytic pyrolysis technologies were prospected at the end.

\section{Introduction}

Biomass as the sole source of organic carbon in the post fossil age, which is only one new energy that provide liquid fuel substitute for oil ${ }^{[1]}$. Liquid fuel technology for biomass production has experienced two stages: Firstly, The first generation biofuels which takes fermentation technology as a representative to product biogas and ethanol, etc. But its production cycle is long , the output is low and the cost is high, can not meet the economic development process of the fuel in the fast, a lot of demand ${ }^{[2]}$; Secondly, The second generation biofuels takes Bio pyrolysis oil as a representative, Although the calorific value of bio oil is not high, it has not been used widely at resent, but its costs is low, the period is short, the future will become the main theme of new energy development ${ }^{[3]}$.

\section{Preparation of liquid fuels from biomass pyrolysis}

\section{Pyrolysis conditions}

Biomass pyrolysis to produce liquid fuel should be carried out in a special atmosphere, Mainly include: inert gas atmosphere; Appropriate pyrolysis temperature; the choice of the appropriate air pressure according to the different reaction, the shorter the gas phase residence time and so on. The general pyrolysis reactor can meet the above requirements, the research of thermal pyrolysis reactor is mainly derived from the petrochemical industry in the crude oil refining device, in recent years, many research institutions to improve the conventional reactor, so that more suitable for biomass pyrolysis reaction process.

\section{Pyrolysis reactor}

Since 1980s, rapid pyrolysis technology has been developed rapidly because of its special advantages in producing liquid fuel. The pyrolysis apparatus, which is already close to the scale of commercial operation $^{[4-5]}$.

Rapid thermal cracking reactor is a key equipment in the whole pyrolysis system, its main characteristics are: very high heating and heat conduction rate, can provide a strict control of the temperature in the reactor, volatile parts quickly leave the reactor. In view of the high yield and 
high yield of biomass pyrolysis, the reaction conditions for the high yield of bio oil were obtained. Synthesis of the existing reactor, mainly including the fluidized bed, ablation reactor, circulating fluidized bed, drainage bed, rotating cone and vacuum moving bed reactor, etc. ${ }^{[6,7]}$.

\section{Drainage bed reactor}

R \& D units mainly in the United States GTRI and Belgium Egemin company. Egemin company in 1991, the scale of its pyrolysis technology to enlarge and achieve commercial applications, but found that the process of the flow of gas to the biomass particles pass heat, the heat transfer rate in the presence of a big problem, and finally suspended the technology in-depth study. GTRI has not been on the scale of its technology expansion.

\section{Vacuum pyrolysis reactor}

Vacuum pyrolysis technology is actually the speed to slow pyrolysis, bio oil yield was low (35\% 40\%). In 2000, Pyrovac successfully established industrial demonstration device of 93t biomass raw material, but because of the high viscosity of bio oil obtained by vacuum pyrolysis, the application market, and the lack of the corresponding application market, the technology has not been further developed after 2002.

\section{Bubbling fluidized bed reactor}

R \& D units are mainly Canadian DynaMotive, class UnionFenosa, Wellman, etc.. Among them, DynaMotive has been established on the daily processing of $8000 \mathrm{t}$ sawdust in the bubbling fluidized bed industrial demonstration plant, bio oil production rate of more than $60 \%$, mainly for gas turbine power generation.

\section{Rotating Cone Reactor}

R \& D units are mainly Holland Twente University and BTG. BTG has established a rotary cone industrial plant in, which has been established in Malaysia, with a yield of more than $60 \%$, oil for boiler combustion and power generation.

\section{Circulating fluidized bed reactor}

R \& D units are mainly ENSYN, Greece, CRES and CPERI, ENEL, Italy, Finland VTT, etc.. ENSYN has developed a variety of different structure of the circulating fluidized bed pyrolysis apparatus, the largest of which is the largest unit of the device to deal with $625 \mathrm{t}$ raw materials. However, the Manltowoc power plant in the United States of the plant to produce a total of bio oil and Coal Co fired power test shows that the combustion characteristics of bio oil is poor, indicating that the use of ENSYN technology can not get good quality of bio oil.

\section{Domestic pyrolysis reactor}

Domestic research on biomass pyrolysis and liquefaction technology started late, and it has not reached the mature stage of foreign countries. However, there has been a lot of research institutions (such as Zhejiang University, East China University of science and technology, Shenyang Agricultural University, Beijing University of chemical technology, Huazhong University of science and technology, Southeast University, Tianjin University) in recent years in the research on the technology and absorb the successful experience of foreign countries at the same time also made a variety of reactor and system ${ }^{[8]}$. Shenyang Agricultural University from 1993 onwards, in cooperation with the Netherlands, and in 1995 from Dutch swallow students matter can technology group, the introduction of a biomass feed rate is $50 \mathrm{~kg} / \mathrm{h}$ rotating cone reactor biomass flash pyrolysis liquefaction equipment ${ }^{[9]}$.

\section{Pyrolysis bio oil properties and its application}

At present, upgrading of bio oil, mainly including four conversion pathways: fluid catalytic cracking (FCC), hydrogenation deoxidization (HDO) and hydrogenation process (HT) and 
decarboxylation process (HDO).

FCC process is generally the quality of bio oil will have a substantial increase, but the yield will be decreased, which is mainly due to the catalytic process of FCC catalyst will be large molecular catalytic cleavage into two small molecules, so that the final cleavage, the final large molecules will be part of the formation of small molecular gas product, so that the oil yield decreased. In the process of FCC, the catalyst is very easy to accumulate. The structure of the fixed bed is not conducive to the regeneration of the catalyst, and the consumption of the catalyst is great. Therefore, the FCC process is not an optimal choice for biomass pyrolysis ${ }^{[10,11]}$.

HDO and HT process although can effectively remove the oxygen in the bio oil, but $\mathrm{H} 2$ consumption is too large, not economically feasible; and the two processes of high pressure, which will cause a lot of energy, it is not safe; in addition, HDO process s existence will even produce some sulfur gas product, which also to the environment pollution caused by. Therefore, HT and HDO process now rarely as a means of upgrading of bio oil ${ }^{[12]}$. The complete DCO process is the best way for bio oil upgrading, the process can generate a large amount of hydrocarbons and the consumption of $\mathrm{H} 2$. But the biggest problem is that the catalyst surface, it is easy to form a large number of coke, which requires the development of new catalyst to solve this problem ${ }^{[13]}$.

In the process of DCO, it is considered that the catalyst surface is easy to accumulate carbon, which is due to the poor performance of the catalyst itself. Some new research suggests that the effective hydrogen carbon is the influence factor of the surface area of the catalyst, and can effectively reduce the carbon deposition on the catalyst, so as to achieve the same effect with the petroleum refining industry by improving the effective hydrogen carbon ratio of the biomass.

Zhang, Huiyan ${ }^{[14]}$ and ZSM-5 were used to catalyze the pyrolysis of the mixture of Matsuki and alcohol. The quality and yield of bio oil were improved, and the carbon deposition on the catalyst decreased. But due to alcohol and pine sawdust optimal catalytic conditions far. Therefore, it is necessary to seek alternatives to other high effective hydrogen carbon ratio.

\section{Conclusions and Outlook}

(1) The second generation of biofuels is more promising than the first generation of biofuels and will become a major market for future liquid fuels;

(2) In three kinds of biomass pyrolysis, the rapid thermal cracking technology will occupy the main stage with its unique advantages. In the process of rapid pyrolysis, bio oil production rate is high, the cycle is short, safe and good, will become the main production of bio oil;

(3) In the mechanism of biomass pyrolysis, the pyrolysis mechanism of cellulose, hemicellulose and lignin was carried out in three different paths.

(4)In a variety of pyrolysis reactors, the fluidized bed reactor has a good continuous response capability, and has been used as the main reactor for the pilot scale test. However, due to the complexity of the operation process, the energy consumption is too large, so the mechanism of the laboratory scale is rarely used, laboratory and more fixed bed reactor for catalytic pyrolysis experiments;

\section{References}

[1] Poliakoff M, Licence P, Green Chemistry, Nature: Sustaniable Technology. 450(2007) 810-812.

[2] Rabelo SC, Carrere H, Maciel Filho R, et al, Production of bioethanol, methane and heat from sugarcane bagasse in a biorefinery concept, Bioresource Technology. 17(2011)7887-7895.

[3] Ragauskas AJ, The path forward for biofuels and biomaterials, Science. 5760(2006) 484-489. 
[4] A.V.Bridgwater, Fast Pyrolysis of Biomass:a Handbook, London, 2005.

[5] H eR, E G, F FJ, Pyrolysis of palm oil residues in malaysia, PyNe Newsletters. 19(2005)2-3.

[6] Hu S, Jess A, Xu M, Kinetic study of Chinese biomass slow pyrolysis: Comparison of different kinetic models, Fuel. 17-18(2007)2778-2788.

[7] Bridgwater AV, Review of fast pyrolysis of biomass and product upgrading, Biomass and Bioenergy. 38 (2012) 68-94.

[8] Liu Ronghou, Lu Nan, Cao Yurui, Rotating cone reactor thermal cracking process and biological experiments, Shenyang Agricultural University. 4(1997) 307-311.

[9] Xiao Gang, pool Chung, NI Ming-jiang, et al, Experimental study on PVC plastic fluidized bed gasification, Fuel Chemistry and Technology. 6(2005)708-712.

[10] Adjaye JD, Bakhshi NN, Production of hydrocarbons by catalytic upgrading of a fast pyrolysis bio-oil. Part I: Conversion over various catalysts, Fuel Processing Technology. 45(1995)161-183.

[11] Vitolo S, Seggiani M, Frediani P, Catalytic upgrading of pyrolytic oils to fuel over different zeolites, Fuel. 78(1999)1147-1159.

[12] Şenol Oİ, Ryymin EM, Viljava TR, et al, Effect of hydrogen sulphide on the hydrodeoxygenation of aromatic and aliphatic oxygenates on sulphided catalysts, Journal of Molecular Catalysis A: Chemical. 1-2(2007)107-112.

[13] Zhang S, Yan Y, Li T, et al, Upgrading of liquid fuel from the pyrolysis of biomass, Bioresource Technology. 5(2005)545-550.

[14] Zhang HY, Carlson TR, Xiao R, et al, Catalytic fast pyrolysis of wood and alcohol mixtures in a fluidized bed reactor, Green Chem. 1(2012) 98-110. 